Studi Francesi

STUDI

Rivista quadrimestrale fondata da Franco Simone

FRANCESI

173 (LVIII | II) | 2014

SERVO (serf, servant, valet, serviteur, laquais,

servante, soubrette, bonne...) a cura di Daniela Dalla

Valle

\title{
Aa. Vv., «Cahiers Mérimée», n. 5
}

\section{Michel Arrous}

\section{OpenEdition}

\section{Journals}

Édition électronique

URL : http://journals.openedition.org/studifrancesi/1897

DOI : 10.4000/studifrancesi. 1897

ISSN : 2421-5856

Éditeur

Rosenberg \& Sellier

Édition imprimée

Date de publication : 1 septembre 2014

Pagination : 387

ISSN : 0039-2944

Référence électronique

Michel Arrous, «Aa. VV., «Cahiers Mérimée», n. 5 », Studi Francesi [En ligne], 173 (LVIII | II) | 2014, mis en ligne le 01 septembre 2014, consulté le 18 septembre 2020. URL : http://journals.openedition.org/ studifrancesi/1897; DOI : https://doi.org/10.4000/studifrancesi.1897

Ce document a été généré automatiquement le 18 septembre 2020

\section{(c) $(1)$}

Studi Francesi è distribuita con Licenza Creative Commons Attribuzione - Non commerciale - Non opere derivate 4.0 Internazionale. 


\title{
Aa. Vv., «Cahiers Mérimée», n. 5
}

\author{
Michel Arrous
}

\section{RÉFÉRENCE}

AA. VV., «Cahiers Mérimée», Paris, Classiques Garnier, 2013, n. 5, pp. 191.

1 Empêchée par la mort de mettre la dernière main à son étude des adaptations lyriques de Mateo Falcone, Marie-Noëlle AUGUSTE laisse avec "Mateo Falcone" à l'opéra (pp. 13-38) un riche témoignage de ses recherches sur les huit opéras inspirés par la nouvelle de Mérimée, composés entre 1839 et 1987 . Afin de restituer le matériau archaïque de la nouvelle, les compositeurs ont puisé dans le patrimoine musical corse et italien, et même dans la musique liturgique pour les prières de Fortunato et de Giuseppina. Francis MARCoIN (L'enfance selon Mérimée, pp. 39-55) lit la même nouvelle selon la perspective du sacrifice de l'enfant. Au moment où Mérimée publie, abondent récits et tableaux édifiants qui ont pour sujet l'enfant ou le gamin. Mérimée renverse l'histoire de l'enfant qu'on se plaît à voir honnête ou sublime en choisissant une "perspective scandaleuse, insupportable pour une mentalité moderne», surtout parce qu'il ne propose «ni célébration ni condamnation». Les multiples sources sont connues, comme les récritures - par exemple, celle du jeune Flaubert qui s'investit dans le personnage -, et les adaptations, ainsi que les incessantes réévaluations auxquelles la nouvelle donne lieu dans les programmes scolaires. À l'exception de Mérimée, la critique de l'époque a prétendu que les romantiques ne savaient pas écrire de comédies. Sylvain LEDDA revient sur cette affirmation et la question du comique romantique (Le comique dans le "Théâtre de Clara Gazul", pp. 57-73). Les insinuations comiques de la notice sur la pittoresque comédienne se déploient dans les saynètes (sous-entendus grivois, comique de situation, comique farcesque, topoï romanesques). L'intérêt de l'étude tient aussi au cadre théorique choisi par Mérimée qui adopte les principes esthétiques de Racine et Shakespeare (prose simple, non respect de l'unité de temps et de lieu, choix d'événements hors de la banalité ordinaire, éléments de distanciation, couleur locale marquée). Parmi les emplois comiques de ce théâtre, on distingue le personnage féminin, surtout celui de la comédienne utilisé à des fins satiriques. On peut d'autant 
plus facilement imaginer un Mérimée classique, célèbre exemple du «style bref», que son système stylistique et narratif est régi par la litote ou la réserve qui consiste à dire moins pour choquer plus, et à «dire clair» pour obscurcir. Christine RODRIGUEZ illustre cette pratique en étudiant la contradiction entre l'expression et le contenu, entre la clarté formelle et l'opacité d'un récit oscillant «entre ce que l'on sait et ne sait pas, ce que l'on croit ou ne croit pas» ("Qui peut le moins peut le plus». Ambiguité du "style sec» dans "La Vénus d'Ille", pp. 75-91). Bousculant des hiérarchies arbitrairement établies entre les différentes vocations de l'homme, Jean BaLSAMo montre que deux des nouvelles les plus connues de Mérimée peuvent être considérées comme les fruits d'un "loisir lettré» (Érudition et création littéraire. "Colomba" et "Carmen", divertissements lettrés, pp. 93-119). Dans la première, Mérimée a exploité son rapport administratif mis en forme dans les Notes d'un voyage en Corse; dans la seconde, la fiction se nourrit d'une anecdote racontée par la comtesse de Montijo et accompagne la rédaction de l'Histoire de Don Pèdre Irr , ainsi que des études ethnographiques et linguistiques su les Gitans. Dans les deux cas «l'érudition est le cadre dans lequel peut se déployer la fiction». S'appuyant sur des articles de Léon de Laborde (1833, rééd. 1841), de Théodore Pavie (1840) et sur des ouvrages consacrés au sommeil et aux rêves publiés entre 1840 et 1870, Jacques SPRANG lit l'énigme de Djoûmane comme un récit de magie traditionnelle et de magnétisme mesmérien (Magie orientale et magnétisme dans "Djoûmane", pp. 121-135). Peter CoGman se demande ce que représentait pour Mérimée le Journal de Samuel Pepys, auquel il consacra un long article donné au «Moniteur universel» de Dalloz (janvier 1869), plutôt qu'au nouveau «Journal officiel de l'Empire français» fondé par le ministre Rouher. Peut-être connaissait-il Pepys dès la fin des années 1820, mais ces notes prises au jour le jour entre 1660 et 1670, il est peu probable qu'il les ait lues avant la fin des années 1860. Les caractéristiques communes aux deux hommes ne manquent pas, à tel point qu'on peut parler de "vies parallèles». Ce qui les rapproche le plus, c'est une conception similaire de la vérité facteur de désordre. Bien informé sur Pepys et son époque, Mérimée intervient sur le texte du mémorialiste, notamment quand il s'agit de religion, pour relever l'oppression puritaine dans le Commonwealth ou, inversement, l'absence de pruderie et la recherche du plaisir sous la Restauration. On retrouve là le Mérimée adversaire résolu du cant, prisant par-dessus tout la sincérité de Pepys dont il se fait une arme pour subvertir les convenances et la moralité hypocrite de ses contemporains. Odile PARSIS-BARUBÉ illustre quelques points de sa thèse d'habilitation (La province et les provinciaux dans la correspondance de Prosper Mérimée, pp. 159-178): l'inspecteur général parcourt la province, affronte son inconfort et sa saleté, et supporte bien des privations - pas plus de cirage à Vézelay qu'à Nevers, Autun ou Lyon de filles à son goût! Il se méfie des érudits et des antiquaires locaux dans lesquels il voit l'«incarnation extrême de la provincialité». Cette cinquième livraison est complétée par la bibliographie de la critique littéraire et historique sur l'œuvre de Mérimée en 2011 (pp. 181-183), dressée par Xavier BoURDENET. 